\title{
Storm time dynamics of auroral electrojets: CHAMP observation and the Space Weather Modeling Framework comparison
}

\author{
H. Wang ${ }^{1, *}$, H. Lühr ${ }^{2}$, A. Ridley ${ }^{1}$, P. Ritter ${ }^{2}$, and Y. Yu ${ }^{1}$ \\ ${ }^{1}$ Department of Atmospheric, Oceanic, and Space Sciences, University of Michigan, Ann Arbor, MI-48109, USA \\ ${ }^{2}$ GeoForshungsZentrum Potsdam, 14473 Potsdam, Germany \\ * On leave from: College of Electronic Informatics, Wuhan University, Wuhan 430079, P. R. China
}

Received: 29 August 2007 - Revised: 14 January 2008 - Accepted: 28 January 2008 - Published: 26 March 2008

\begin{abstract}
We investigate variations of the location and intensity of auroral currents during two magnetic storm periods based on magnetic field measurements from CHAMP separately for both hemispheres, as well as for the dayside and nightside. The corresponding auroral electrojet current densities are on average enhanced by about a factor of 7 compared to the quiet time current strengths. The nightside westward current densities are on average 1.8 (2.2) times larger than the dayside eastward current densities in the Northern (Southern) Hemisphere. Both eastward and westward currents are present during the storm periods with the most intense electrojets appearing during the main phase of the storm, before the ring current maximizes in strength. The eastward and westward electrojet centers can expand to $55^{\circ}$ MLat during intense storms, as is observed on 31 March 2001 with $D_{s t}=-387 \mathrm{nT}$. The equatorward shift of auroral currents on the dayside is closely controlled by the southward IMF, while the latitudinal variations on the nightside are better described by the variations of the $D_{s t}$ index. However, the equatorward and poleward motion of the nightside auroral currents occur earlier than the $D_{s t}$ variations. The Space Weather Modeling Framework (SWMF) can capture the general dynamics of the storm time current variations. Both the model and the actual data show that the currents tend to saturate when the merging electric field is larger than $10 \mathrm{mV} / \mathrm{m}$. However, the exact prediction of the temporal development of the currents is still not satisfactory.
\end{abstract}

Keywords. Ionosphere (Auroral ionosphere; Electric fields and currents; Modeling and forecasting)

Correspondence to: H. Wang

(whui@umich.edu)

\section{Introduction}

The intensification and equatorward expansion of the auroral electrojet are characteristic features of geomagnetic storm disturbances (Chapman and Bartels, 1940; Feldstein et al., 1997). The auroral electrojet indices (AE, AL, AU) are introduced for the description of the intensity of electrojets (Davis and Sugiura, 1966). The AE index tends to saturate during the main phase of the intense magnetic storm, which is regarded as an artifact caused by the equatorward shift of the auroral electrojet beyond the standard AE network (Akasofu, 1981; Feldstein et al., 1997). Around midnight, the electrojet center lies typically at $\sim 60^{\circ}$ MLat (magnetic latitude) for $D_{s t} \sim-100 \mathrm{nT}$ while at $\sim 54^{\circ}$ MLat for $D_{s t} \sim-300 \mathrm{nT}$ (e.g. Feldstein et al., 1997), which is well equatorward of the 12 AE observatories, located between $63^{\circ}$ and $70^{\circ}$ MLat (Feldstein et al., 1997). However, several studies argued that the main electrojet centers never shift equatorward of $60^{\circ}$ MLat regardless of the magnetic storm levels (e.g. Weimer et al., 1990; Ahn et al., 2005), although the conclusion of Ahn et al. (2005) was based on the events when the lowest AE station was on the nightside. In this aspect, the AE saturation is assumed to be real and a result of the nonlinear nature of the magnetosphere-ionosphere coupling (Kan et al., 1988).

Meng (1986) reported that the dayside aurora was displaced by a few degrees less equatorward than the nightside region near the peak of the magnetic storm, and the midnight auroral oval recovered more slowly than the noon sector during the storm recovery phase. Wang et al. (2006) found that the equatorward shift of field-aligned currents (FACs) on the dayside was closely correlated with the southward IMF $B_{z}$ while the equatorward expansion of the nightside FACs was better described by the variations of the $D_{s t}$ index. Since auroral electrojets are embedded in the auroral oval and closely related to FACs, it is thus expected that the equatorward expansion of the auroral electrojets also exhibit the day-night asymmetries in response to the solar wind parameters and storm phases.

Published by Copernicus Publications on behalf of the European Geosciences Union. 
In addition, eastward and westward electrojets are found to behave differently during storms. For example, the equatorward shift was much more pronounced for the eastward currents than for the westward (Rostoker and Phan, 1986). Kamide (1979) concluded that eastward electrojets disappeared when westward electrojets were very intense, thus, $\mathrm{AL} \gg \mathrm{AU}$ was reported during the storm main phases. In contrast, Feldstein et al. (1997) found that eastward electrojets existed in every magnetic storm, and eastward electrojets moved only equatorward while westward electrojets moved both poleward and equatorward. They pointed out if only the region of auroral latitudes was considered, the impression can be created that eastward electrojets disappeared during the course of intense magnetic storms. Previous studies showed that the most intense westward electrojet was most often observed around 03:15 MLT and the eastward electrojet around 17:30 MLT (Allen and Kroehl, 1975). With satellite observations close to these two local time sectors, comparative investigations of eastward and westward electrojets dynamics during storm periods can be performed.

The discussions and suggestions about the relationship between the auroral electrojet and ring current are quite controversial. For example, some authors claimed that the ring current intensification occurred earlier than the auroral electrojet (e.g. Akasofu and Chapman, 1963; Akasofu and Yoshida, 1966). Others showed that auroral electrojets often increased before the ring current increased (Pudovkin et al., 1968), therefore, the ring current formation was claimed to be caused by the substorm events (Rostoker, 1997). However, Siscoe and Petschek (1997) indicated that there was no direct relation between substorm and ring current intensification and they were more like the two independent processes which are caused possibly by the same source (Grafe and Feldstein, 2000). By comparing the dynamics of auroral electrojets with the variations of $D_{s t}$ this problem will be examined in this study.

This work includes: (1) a report on the high resolution CHAMP observations of the dayside and nightside auroral electrojet current density and position during the 31 March 2001 and 17 April 2002 storms; (2) an investigation of the variation of the dayside and nightside electrojets in association with $D_{s t}$ and solar wind parameters; (3) a comparison of the storm time dynamics of the eastward and westward auroral electrojets; and (4) a comparison between CHAMP observations and the Space Weather Modeling Framework (SWMF) model outputs. In the following section we describe the instrumentation and data processing. The SWMF model will also be briefly introduced. The event analysis of the observations and data-model comparison is presented in Sect. 3. In Sect. 4 the results are discussed in the context of previous publications. Section 5 summarizes the conclusions drawn from the observations and data-model comparison.

\section{Instrumentation and data processing}

The geoscientific satellite CHAMP was launched on 15 July 2000 from the Russian cosmodrome Plesetsk into a circular, near-polar orbit $\left(87.3^{\circ}\right.$ inclination, $\sim 93 \mathrm{~min}$ orbit period) (Reigber et al., 2002). During the two considered storms CHAMP was approximately in the late afternoon (daytime) - early morning (nighttime) meridian (15:00 03:00 MLT at $475 \mathrm{~km}$ height for the March 2001 storm and 16:00 04:00 MLT at $421 \mathrm{~km}$ height for the April 2002 storm). This constellation enables us to study the dependence of the dayside and nightside auroral currents on solar wind parameters and storm phases. The ionospheric Hall currents, here the source-free ionospheric current components, are determined from the scalar magnetic field measurements. The Hall current is approximated by a series of infinite line currents, separated by 1 degree, which are placed in the ionospheric $\mathrm{E}$ region at a height of $115 \mathrm{~km}$. The technique of determining the current strength of each line by inverting the variations in the total magnetic field has been developed by Olsen (1996). Moretto et al. (2002) has applied this method later to Ørsted data. The reliability of this approach has been demonstrated in a statistical study where current density estimates from CHAMP were directly compared with independent determinations from ground (Ritter et al., 2004). The solar wind parameters used in this study are measured by the ACE satellite. The solar wind data have been propagated from the ACE satellite to the magnetopause with the minimum variance method outlined in Weimer et al. (2003).

The Space Weather Modeling Framework (SWMF) model will only be described briefly since it has been fully detailed elsewhere (e.g. Tóth et al., 2005). The SWMF has the ability to couple numerical domain models flexibly and efficiently, including models of the solar corona, the heliosphere, the magnetosphere, ionosphere and thermosphere. This framework enables simulations that were not possible with the individual physics models and it is possible to be run in almost real time on large computer systems. The SWMF used in this work includes the BATSRUS model to simulate the magnetosphere of the Earth (Powell et al., 1999), RCM to simulate the Inner Magnetosphere domain (Toffoletto et al., 2003), and the model by Ridley et al. (2004) to describe the ionospheric electrodynamics. The time-varying IMF and solar wind conditions measured by the ACE satellite are used as inputs at the front boundary $\left(32 R_{E}\right)$. Various papers have described these separate domain models and the results of the coupled simulations that can be achieved utilizing these models (e.g. De Zeeuw et al., 2004; Tóth et al., 2007; Wang et al., 2008). 

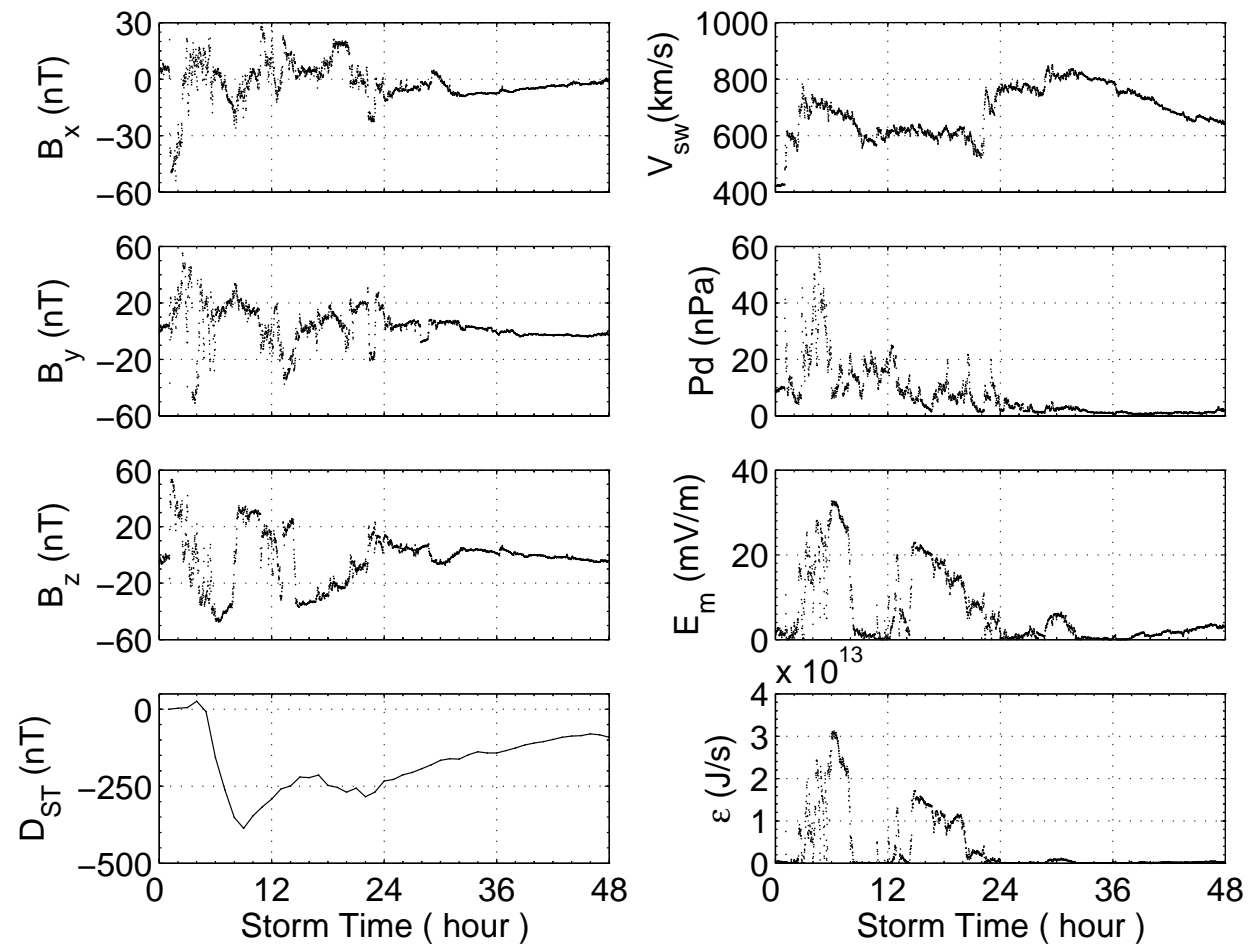

Fig. 1. Typical storm-time solar wind parameters including IMF $B_{x}, B_{y}, B_{z}$ components in GSM coordinate system, as well as velocity, $v_{s w}$, dynamic pressure, $P_{d}$, merging electric field, $E_{m}$, Akasofu parameter, $\varepsilon$, and $D_{s t}$ variations on 31 March-1 April 2001.

\section{Events studies}

\subsection{The storms on 31 March-1 April 2001}

A succession of two intense storms occurred on 31 March1 April 2001 and were accompanied by extreme geophysical conditions. We will refer to the individual hours as Storm Time (ST). Figure 1 shows the time history of 8 quantities related to the magnetic activity on these two days. From left to right it contains the components of the IMF $B_{x}, B_{y}, B_{z}$ in GSM coordinates, $D_{s t}$ index, solar wind velocity, $v_{s w}$, dynamic pressure, $P_{d}$, merging electric field, $E_{m}=v_{s w} \sqrt{B_{y}^{2}+B_{z}^{2}} \sin ^{2}(\theta / 2)($ Kan and Lee, 1979), and Akasofu parameter, $\varepsilon=1 / \mu_{0} v_{s w}\left(B_{x}^{2}+B_{y}^{2}+B_{z}^{2}\right) \sin ^{4}(\theta / 2) l_{0}^{2}$ (Akasofu, 1979), where $\theta$ is the clock angle, and $l_{0}$ is a constant scale length, $\simeq 7$ Earth radii.

We use the $D_{s t}$ index to characterize the two storm intervals. The minimum $D_{s t}$ index was $-387 \mathrm{nT}$ around 09:00 UT and $-284 \mathrm{nT}$ around 22:00 UT. The IMF $B_{z}$ decreased to $-47.5 \mathrm{nT}$ around $06: 35 \mathrm{UT}$ and to $-37 \mathrm{nT}$ around 14:58 UT. The peak values of the energy input, as defined by $\varepsilon$, were about $3.1 \times 10^{13} \mathrm{~J} / \mathrm{s}$ around $06: 18 \mathrm{UT}$ and $1.7 \times 10^{13} \mathrm{~J} / \mathrm{s}$ around $14: 57 \mathrm{UT}$, almost at the same time $E_{m}$ peaks attained values of about $32.7 \mathrm{mV} / \mathrm{m}$ and $22.9 \mathrm{mV} / \mathrm{m}$, respectively. The $v_{s w}$ jumped towards $782 \mathrm{~km} / \mathrm{s}$ and $773 \mathrm{~km} / \mathrm{s}$ around 03:00 and 29:10 UT, respectively. $P_{d}$ peaked at about $59.8 \mathrm{nPa}$ around 04:43 UT.
Figure 2 shows the MLat and UT distribution of the peak eastward and westward ionospheric currents as deduced from CHAMP measurements. The density of the currents are indicated by the circle size. Separate frames are used for the dayside and nightside in both hemispheres. Red circles correspond to eastward currents and blue westward currents. Overplotted is the variation of the $D_{s t}$ index.

Both eastward and westward currents occur during storm periods with the most intense appearing in the storm main phase before the $D_{s t}$ peaks. The peak densities are not always found in the most equatorward currents, and these strong currents do not coincide with the peak values of $E_{m}$ or $\varepsilon$ in a one to one correspondence. At daytime peak eastward current densities are larger than westward, while on the nightside peak westward current densities are larger than the eastward. In the following, we consider mainly eastward currents (electrojets) on the daytime and westward currents (electrojets) on the nighttime in this study, if not state differently.

It can be seen in Fig. 2 that the peak densities of the eastward and westward electrojets are not always found in the same satellite orbit. For example, in the Southern Hemisphere on the dayside the eastward electrojet peaks around 06:56 UT at $-55^{\circ}$ MLat, with an amplitude of $0.93 \mathrm{~A} / \mathrm{m}$, while on the nightisde the westward electrojet peaks around 08:12 UT, at $-54^{\circ}$ MLat, with an amplitude of $-2.12 \mathrm{~A} / \mathrm{m}$. The nightside peak current is larger by a factor of 1.52 (1.11) 

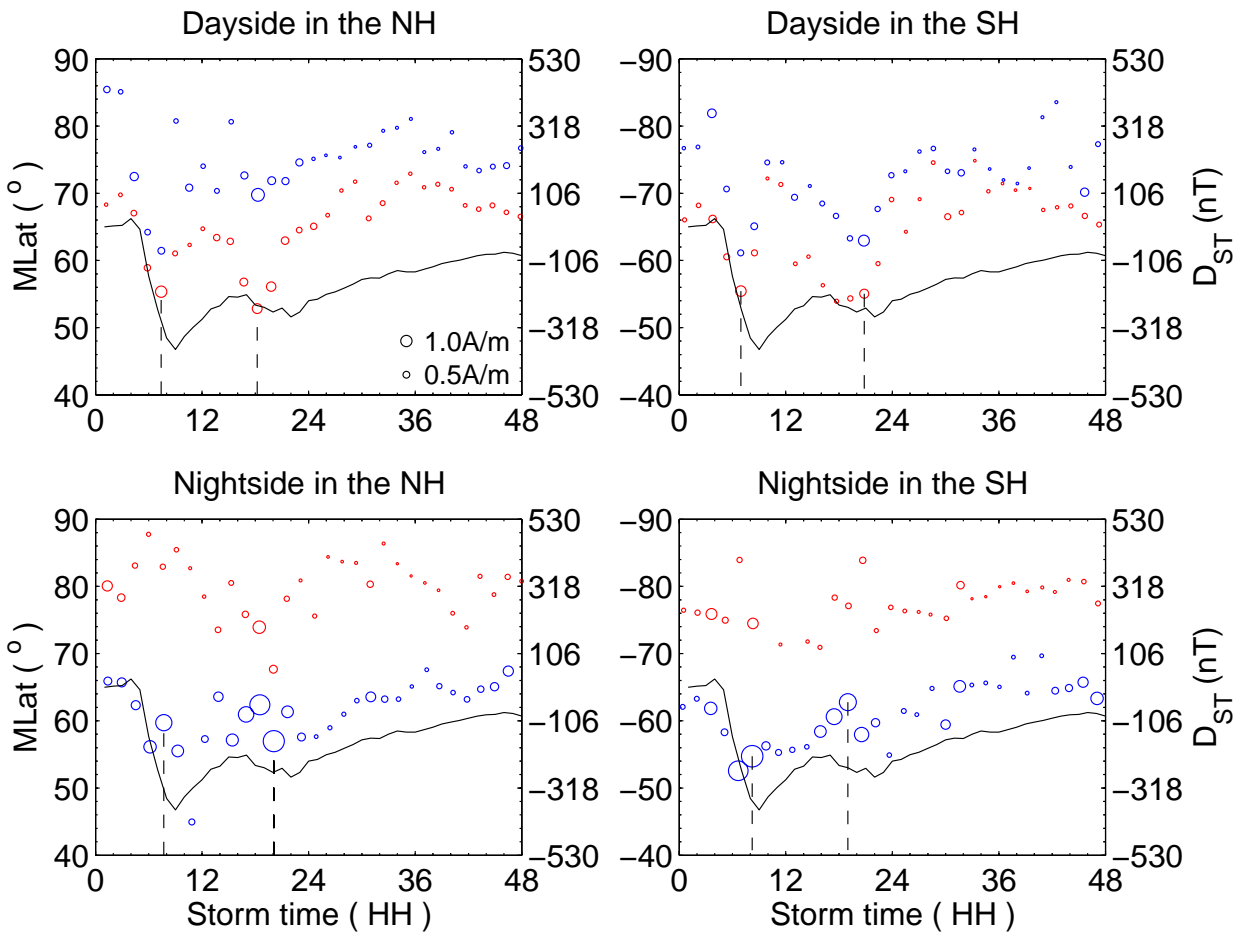

Fig. 2. The time and location of the peak eastward and westward ionospheric currents per orbit observed by CHAMP at the daytime (15:00 MLT) (top) and nighttime (03:00 MLT) (bottom) sectors in the Northern (left) and Southern (right) Hemispheres on 31 March-1 April 2001. The current densities are indicated by the circle size. Eastward electrojets are denoted as red while westward as blue. The vertical dashed lines indicate the maximum densities of the equatorward part of the auroral currents.

Table 1. The peak current density of the auroral electrojets on the dayside and nightside in the Northern (Southern) Hemispheres for the March 2001 (1 2) and April 2002 (1 4) events.

\begin{tabular}{|c|c|c|c|c|c|c|c|c|c|c|c|c|}
\hline & \multicolumn{6}{|c|}{ north } & \multicolumn{6}{|c|}{ south } \\
\hline & \multicolumn{3}{|c|}{ day } & \multicolumn{3}{|c|}{ night } & \multicolumn{3}{|c|}{ day } & \multicolumn{3}{|c|}{ night } \\
\hline & $\mathrm{UT}(\mathrm{HH})$ & $\operatorname{MLat}\left({ }^{\circ}\right)$ & $\mathrm{j}(\mathrm{A} / \mathrm{m})$ & $\mathrm{UT}(\mathrm{HH})$ & $\operatorname{MLat}\left({ }^{\circ}\right)$ & $\mathrm{j}(\mathrm{A} / \mathrm{m})$ & UT(HH) & $\operatorname{MLat}\left(^{\circ}\right)$ & $\mathrm{j}(\mathrm{A} / \mathrm{m})$ & UT(HH) & $\operatorname{MLat}\left({ }^{\circ}\right)$ & $\mathrm{j}(\mathrm{A} / \mathrm{m})$ \\
\hline March storm-1 & $07: 23$ & 55 & 1.03 & $07: 41$ & 60 & -1.57 & $06: 56$ & -55 & 0.93 & 08:12 & -54 & -2.12 \\
\hline March storm-2 & $18: 13$ & 55 & 0.84 & 20:04 & 57 & -2.08 & $20: 50$ & -55.1 & 0.78 & $19: 00$ & -62.8 & -1.65 \\
\hline April storm-1 & $15: 05$ & 66.3 & 0.89 & $16: 25$ & 59.5 & -0.98 & $12: 34$ & -69.2 & 0.56 & $11: 11$ & -67.5 & -1.26 \\
\hline April storm-2 & $33: 30$ & 63.88 & 0.67 & $27: 15$ & 63.2 & -1.03 & $29: 30$ & -61.3 & 0.56 & $34: 24$ & -62.3 & -1.21 \\
\hline April storm-3 & $58: 18$ & 66.1 & 1.21 & $65: 48$ & 59.1 & -1.18 & $68: 12$ & -63.3 & 0.56 & $65: 12$ & -62.9 & -0.91 \\
\hline April storm-4 & $76: 48$ & 66.2 & 0.76 & $76: 30$ & 65.7 & -1.44 & $78: 54$ & -62.0 & 0.56 & $76: 06$ & -58.8 & -1.21 \\
\hline
\end{tabular}

than the dayside current in the Northern (Southern) Hemisphere for the first storm and 2.5 (2.12) for the second storm. The peak densities of electrojets for the first storm are not always larger than those for the second storm although $D_{s t}$ is significantly larger for the first one. However, we should recall that the CHAMP spacecraft samples each polar region only once every $93 \mathrm{~min}$ and may have missed several larger events. A detailed summary of the peak eastward and westward currents for these events is given in Table 1. The table lists the time, MLat, and value of the largest current density detected by CHAMP for both the day and nightside in both the Northern and Southern Hemispheres.
The total current intensities of the eastward and westward currents are compared with the variations of $D_{s t}$, as shown in Fig. 3. Here the total current represents the integrated current densities along satellite orbit separately for the eastward and westward currents. The total intensities of the westward currents are larger than that of the eastward currents on both the dayside and nightside. This is not surprising since intense westward currents cover in this event much wider regions in latitude than the eastward currents. The peak intensities are marked during the main phases of the two storms. The comparison of the integrated current values and the current density values shows that they peak almost synchronously. 

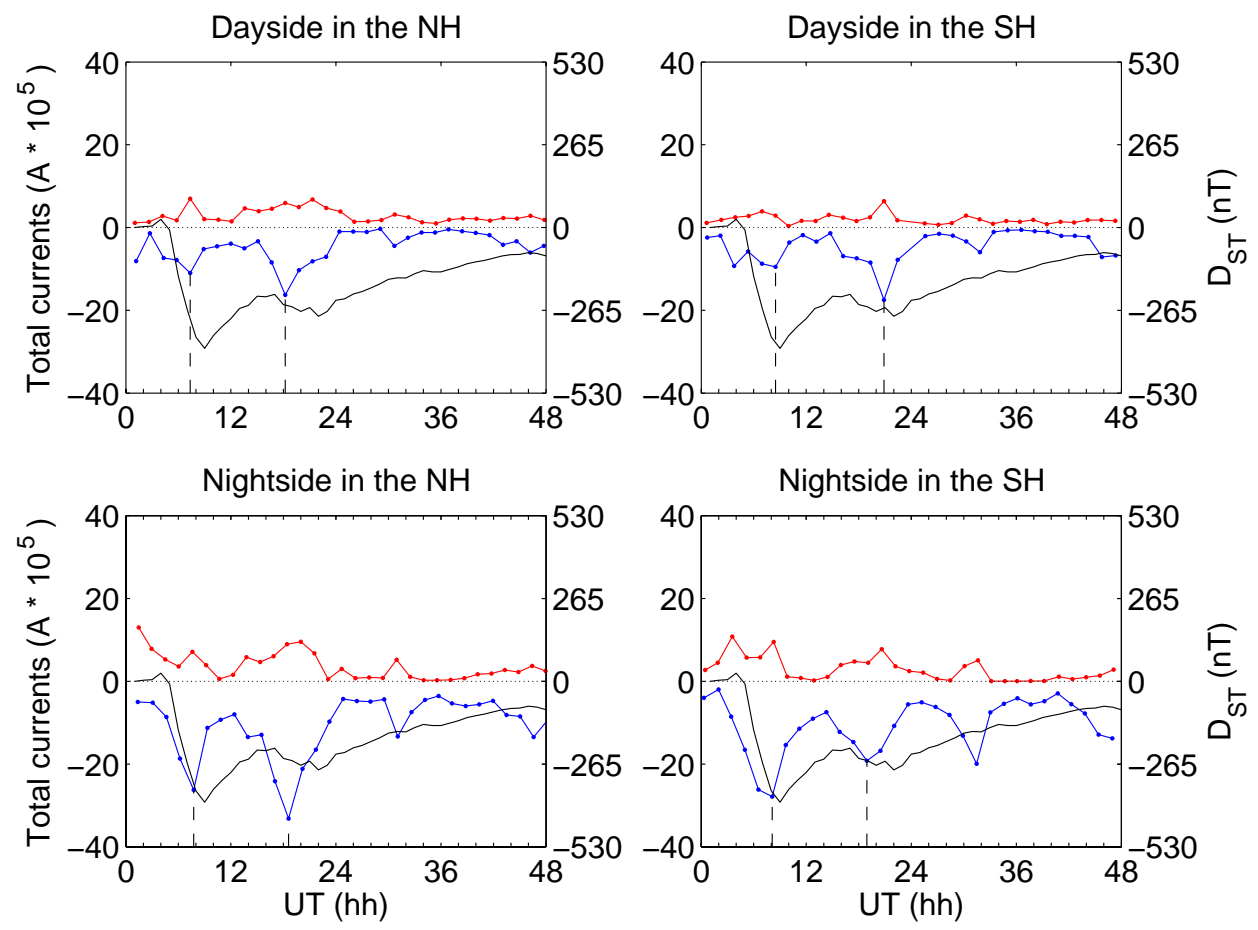

Fig. 3. Storm-time integrated eastward (red) and westward (blue) currents observed by CHAMP together with the variations of $D_{s t}$ index (black) in the daytime (top) and nighttime (bottom) sectors in the Northern (left) and Southern (right) Hemispheres on 31 March-1 April 2001. The vertical dashed lines indicate the maximum intensities of the equatorward part of the total auroral currents.
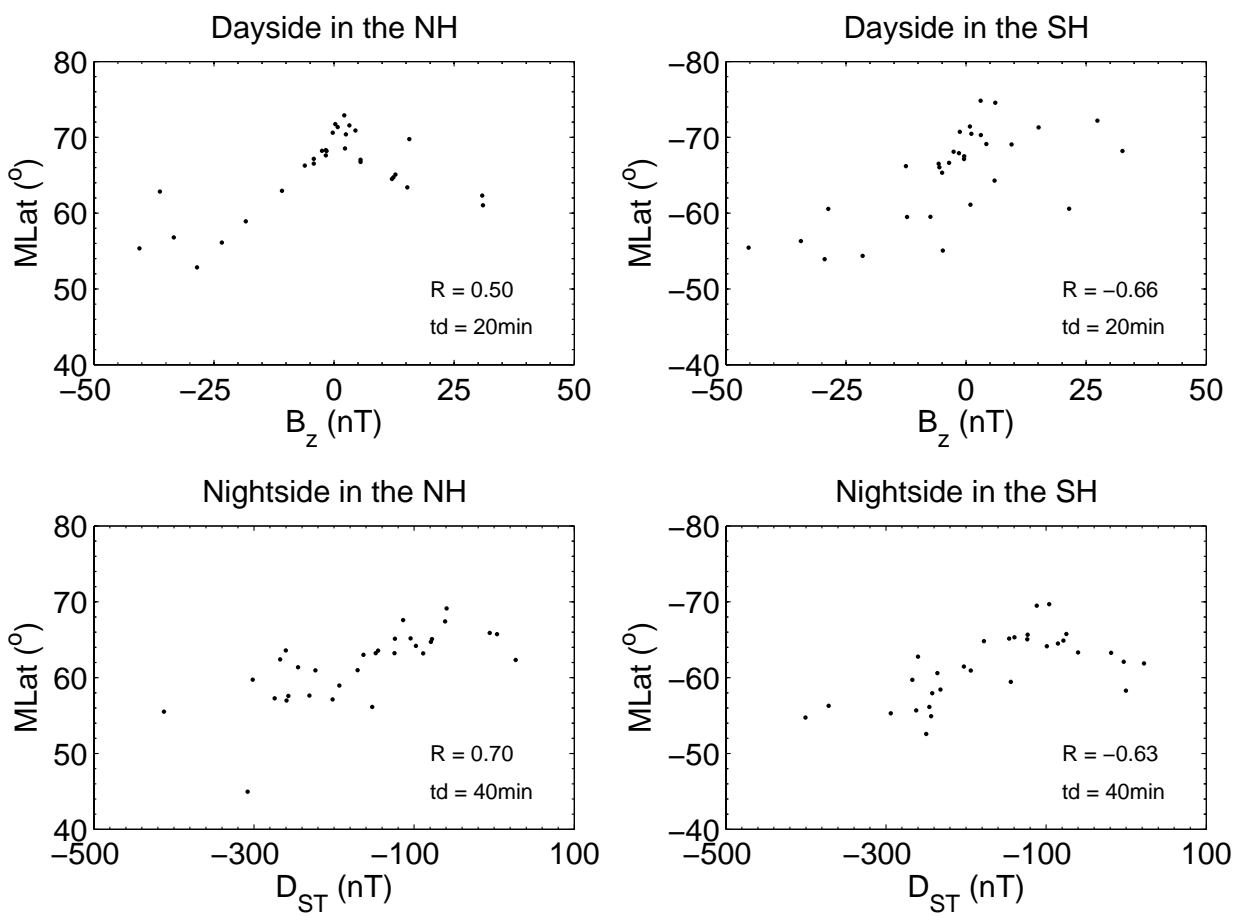

Fig. 4. Correlation analysis of the MLat of the peak current densities with the 20 min time delayed IMF $B_{z}$ and the 40 min time delayed $D_{s t}$ in both hemispheres on 31 March-1 April 2001. The correlation coefficient and the time delay are shown. In the top row the eastward current is compared with IMF $B_{z}$, below westward currents and $D_{s t}$ are shown. 

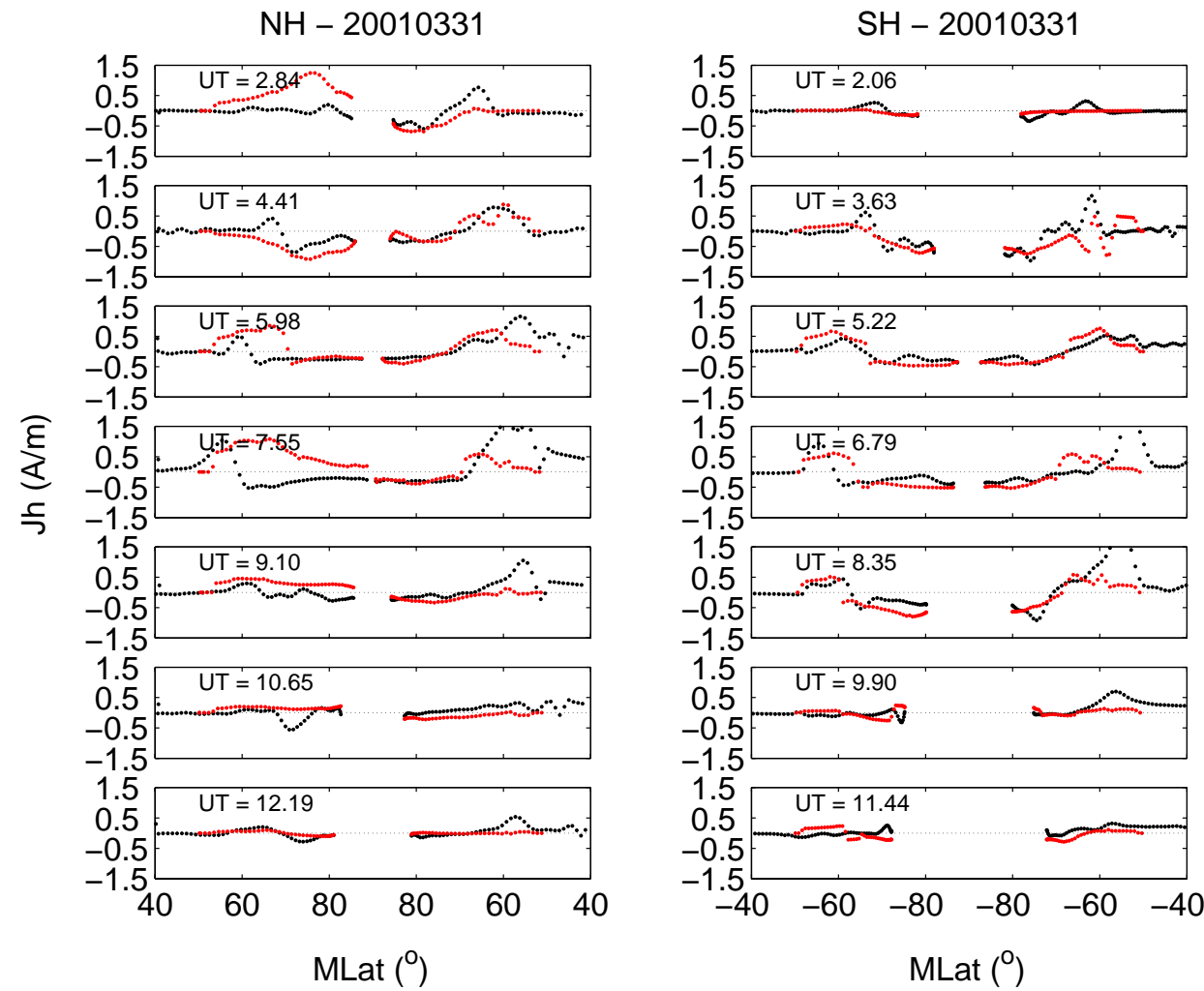

Fig. 5. Storm-time auroral electrojets for individual CHAMP passes over the north and south poles between 02:00 UT and 13:00 UT, covering the main phase of the first storm on 31 March 2001. Black is CHAMP observation and red is SWMF model prediction. For each orbit segment, left part is on the dayside and right is on the nightside. The positive current on the dayside corresponds to an eastward electrojet, while on the nightside it corresponds to a westward electrojet.

Another point that can be seen in Fig. 2 is the equatorward expansion of both the eastward and westward currents as $D_{s t}$ decreases. The peak density of the eastward electrojet on the dayside shifts to $55^{\circ}$ MLat, and the westward electrojet on the nightside shift below $45^{\circ}$ MLat. The latitudinal width of the westward electrojet region on the nightside spreads over a wide range of about $20^{\circ}$ in latitude (not shown in the figures). The equatorward expansion and poleward retreat of the auroral currents occur earlier than the variation of $D_{s t}$. The equatorward boundary of the dayside electrojet is poleward of the nightside electrojet by about $10^{\circ}$ during the first storm but equatorward of the nightside electrojet by about $5^{\circ}$ during the second one. The times at which the nightside westward electrojets reach their minimum latitudes occur later than that of the dayside eastward electrojets, and the dayside eastward electrojets show a more obvious poleward retreat than the nightside westward electrojets. The motion of the equatorward borders of the intense electrojets on the nightside seem to correlate with $D_{s t}$ reasonably well. But on the dayside the motion of the equatorward boundaries of electrojets does not as well correlate with $D_{s t}$. It demonstrates that the latitudinal variation of the electrojet on the dayside followed IMF $B_{z}$ quite well. These features become clearer when looking at
Fig. 4, where the latitudes of the peak densities of electrojet currents in both hemispheres on the dayside (nightside) are compared with the variations of the $20 \mathrm{~min}(40 \mathrm{~min}$ ) time delayed $B_{z}\left(D_{s t}\right)$. The time delay (20 and $40 \mathrm{~min}$ ) is obtained from a cross-correlation. It can be seen from Fig. 4, when $B_{z}<-25 \mathrm{nT}$ or $D_{s t}<-300 \mathrm{nT}$ the latitudinal position of the dayside or the nightside electrojets tend to saturate in both hemispheres.

The auroral electrojets between 02:00 UT and 12:00 UT covering the main phase of the first storm on 31 March 2001 are compared to the current predictions of the SWMF model outputs, as shown in Fig. 5. CHAMP passes from the late afternoon (daytime) to the early morning (nighttime) (from left to right in the Fig. 5). The red curve depicts the model output and the black curve represents the satellite measurement. Positive values on the left dayside correspond to eastward electrojets while on the right nightside they correspond to westward electrojets. Overall, the present simulations can yield the ranges of the current densities and locations "well", although the exact prediction of the temporal development of the currents is still not satisfactory. The peak current densities are not expected to occur simultaneous in the CHAMP observations and SWMF results. There is an underestimation 

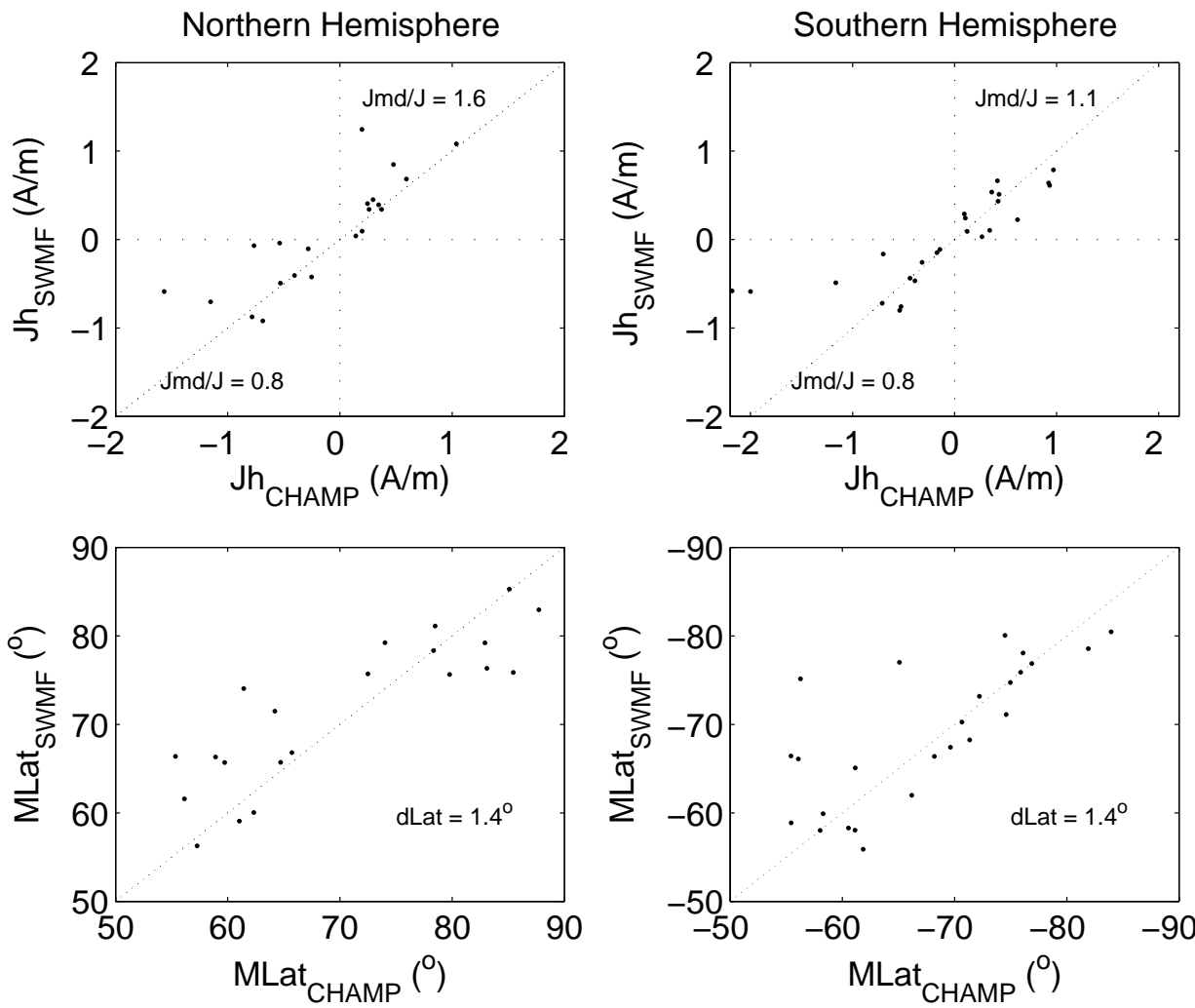

Fig. 6. The top two panels show the peak eastward and westward current densities observed by CHAMP versus those predicted by SWMF in both hemispheres. The bottom two panels display the MLat of the peak current densities observed by CHAMP versus those predicted by SWMF in both hemispheres.

of the amplitudes of westward electrojets and an overestimation of the amplitudes of eastward electrojets, which is more obvious in the Northern Hemisphere. Weak eastward eletrojets (negative) are found equatorward of the dominant westward electrojet (positive) on the nightside after 05:00 UT, which are thought to be associated with the sub-auroral polarization stream (SAPS). Burke et al. (2000) reported also observations of SAPS appearing continuously during the ring current buildup associated with the main phase of a geomagnetic storm. The model cannot reproduce the SAPS features. The model currents tend to be more poleward than the observations, especially between 05:00 and 09:00 UT. These features can be seen more clearly in Fig. 6, where the top two panels show the peak eastward (positive) and westward (negative) currents observed by CHAMP versus those predicted by SWMF in both hemispheres. The average ratio between the model and observations are about $1.6(1.1)$ for the eastward electrojets and about $0.8(0.8)$ for the westward electrojets in the Northern (Southern) Hemispheres. The bottom two panels show the latitudes of the peak current densities observed by CHAMP versus those predicted by SWMF. The SWMF currents tend to be located about $1.4^{\circ}$ MLat more poleward in both hemispheres than the observations.

\subsection{The storms on 17-21 April 2002}

The observations of the four successive April storms will be presented in the same format as the March storms. Figure 7 shows the time history of 8 quantities related to the magnetic activity on 17-21 April 2002. From left to right it contains the components of the IMF $B_{x}, B_{y}, B_{z}$ in GSM coordinates, $D_{s t}$ index, solar wind velocity, $v_{s w}$, dynamic pressure, $P_{d}$, merging electric field, $E_{m}$, and Akasofu parameter, $\varepsilon$.

The $D_{s t}$ index reached $-98,-127,-126$, and $-149 \mathrm{nT}$, around 18:00, 32:00, 67:00, and 81:00 ST. The IMF $B_{z}$ fluctuated a lot during the main phase of the first storm with a miminum of $-31 \mathrm{nT}$ around 15:35 ST. It exhibited another three minima of $-13.6,-18.6,-19.2 \mathrm{nT}$ around 29:28, 60:00, 72:07 ST. The peak values of the energy input, as defined by $\varepsilon$, were about $11,2,5.2,5.3 \times 10^{12} \mathrm{~J} / \mathrm{s}$ around $15: 35,25: 30,58: 30,72: 30 \mathrm{ST}$. Almost at the same time $E_{m}$ peaks attained values of about $16.1,7,13.1,11.2 \mathrm{mV} / \mathrm{m}$. The $v_{s w}$ jumped up to $625,700,666 \mathrm{~km} / \mathrm{s}$ around 22:00, 57:30, 77:30 ST. $P_{d}$ peaked at $26.2,7.4,13.6 \mathrm{nPa}$ around $11: 42$, 58:30, 76:36 ST, respectively.

Figure 8 demonstrates the coexistence of the enhanced eastward and westward currents during the April magnetic storm. The strongest electrojets are found again during 

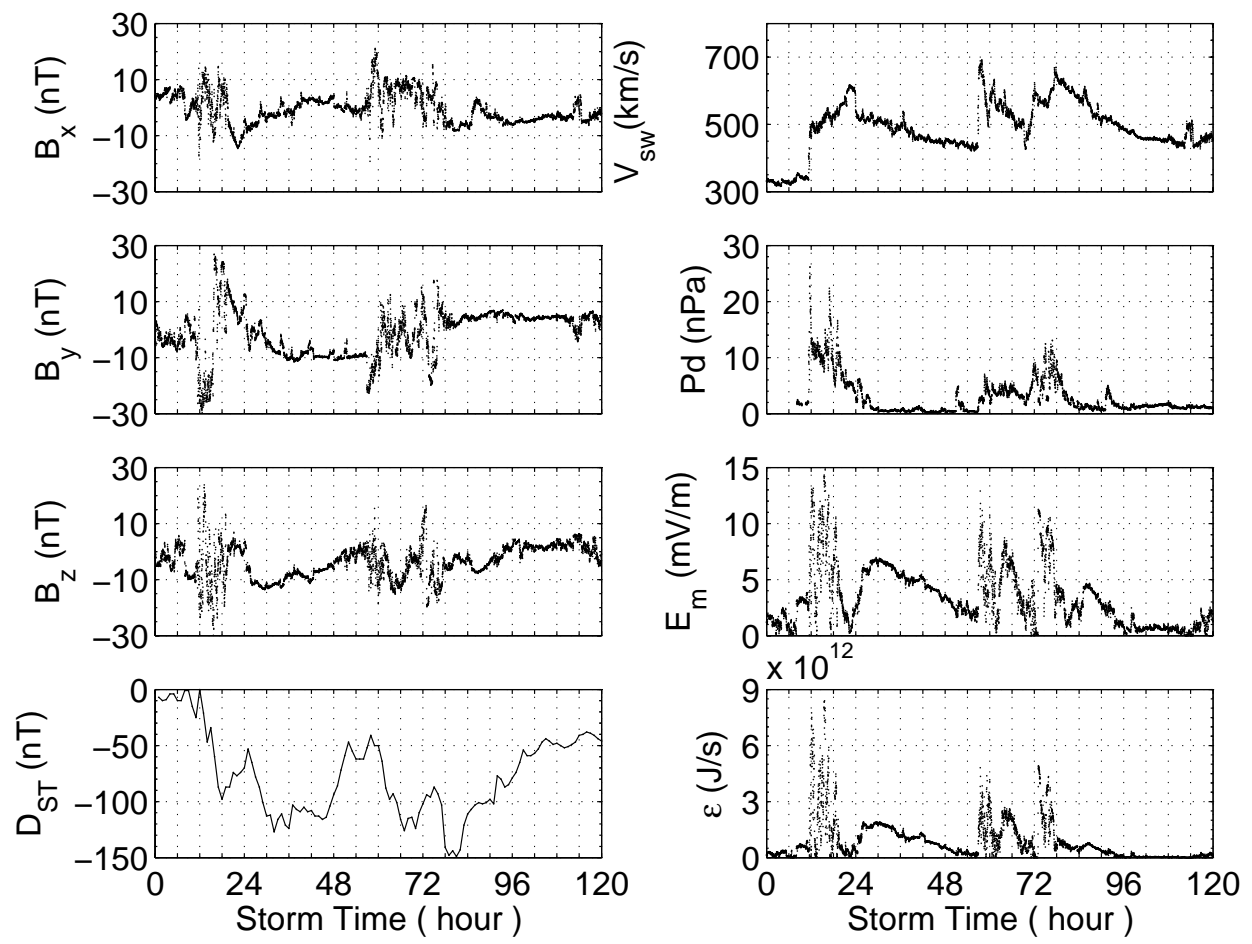

Fig. 7. The same as Fig. 1 but for the 17-21 April 2002 event.
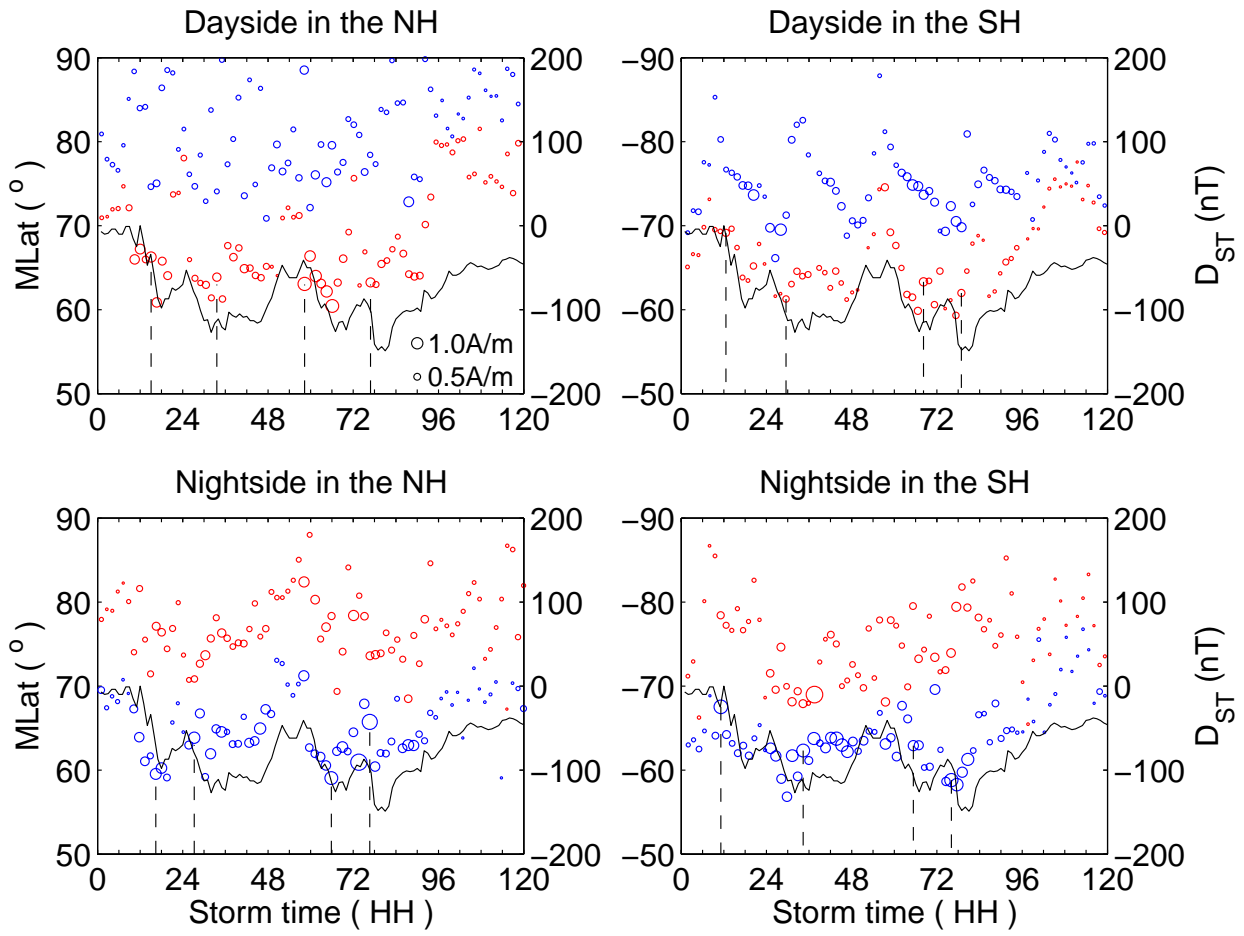

Fig. 8. The same as Fig. 2 but for the 17-21 April 2002 event. 

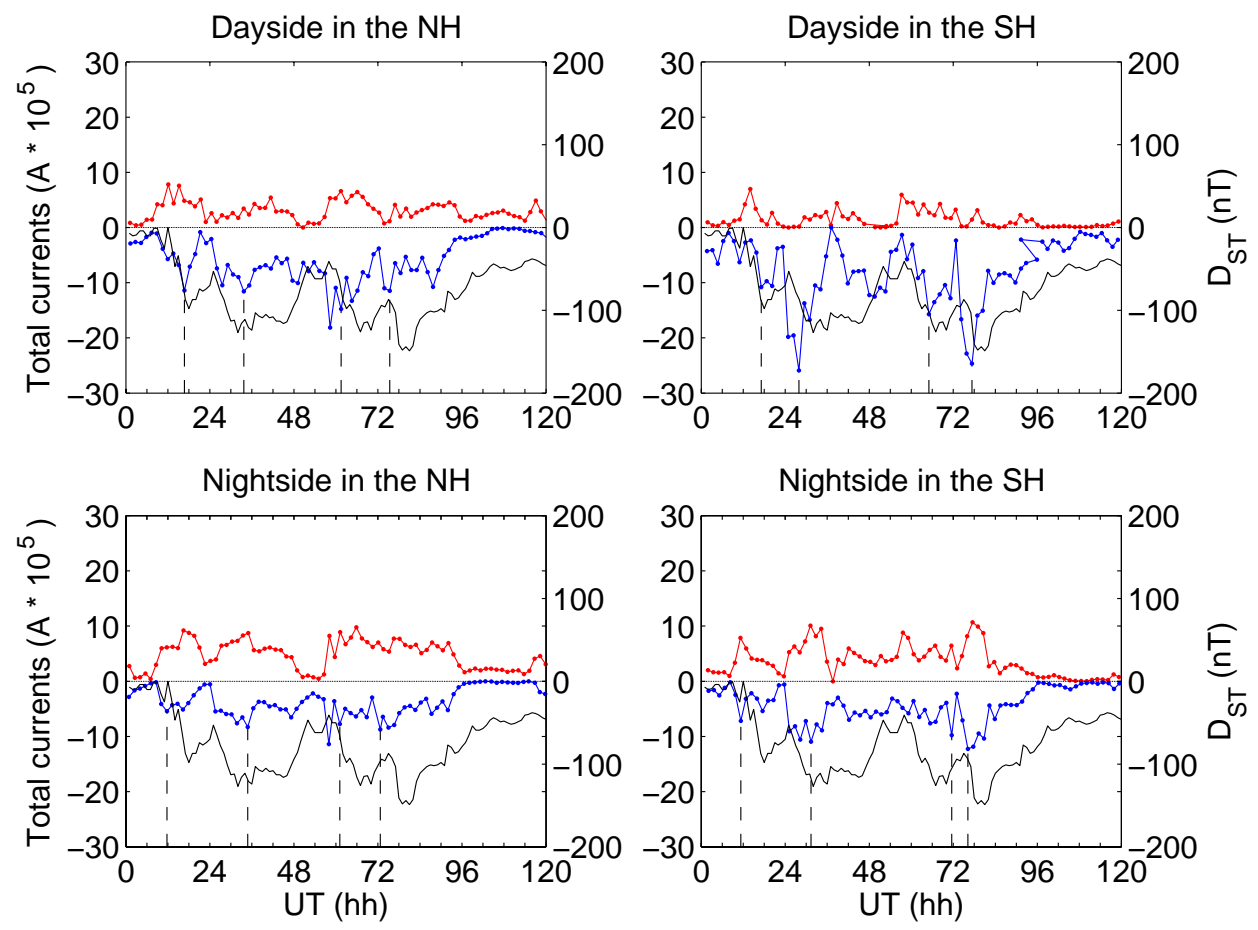

Fig. 9. The same as Fig. 3 but for the 17-21 April 2002 event.

the main phase of the storms, before the ring current $\left(D_{s t}\right)$ peaked. The peak current densities do not coincide with the most equatorward currents in both hemispheres, neither with the maxima of $E_{m}$ nor $\varepsilon$. During the first storm, the westward electrojets on the nightside are larger by a factor of 1.11 (2.25) when compared to the eastward electrojets on the dayside in the Northern (Southern) Hemisphere. A detailed summary of the peak current densities is also given in Table 1. In the next section we will discuss the similarities and differences of auroral current characteristics for all the events.

The integrated current intensities in comparison with the variations of the $D_{s t}$ index are shown in Fig. 9. Similar to the March storm, the total intensities of westward currents are larger than the eastward parts on the dayside, but differently from the March storms, the total intensities of westward currents are smaller than or comparable to the eastward parts on the nightside, which is more obvious in the Northern Hemisphere than in the Southern Hemisphere. The latitudinal width of currents located poleward is much wider than those with opposite polarity more equatorward. This is valid on the dayside and nightside. The integrated currents and the current density values attain their peaks almost synchronously.

Figure 8 exhibits the equatorward expansion of both the eastward and westward currents as the storm develops. For the first storm, the eastward electrojets on the dayside shift to $62^{\circ}$ MLat, and the westward electrojets on the nightside shift below $58^{\circ}$ MLat. The equatorward expansion and poleward retreat of auroral currents occur both earlier than the variation of $D_{s t}$. The auroral currents shift to their lowest latitude before $D_{s t}$ reaches its minimum. The equatorward boundary of currents on the dayside is found poleward of that on the nightside by about $2^{\circ}$ on average. The nightside westward electrojets reach their minima latitudes later than the dayside eastward electrojets, and the dayside eastward currents exhibit a more obvious poleward retreat than the nightside westward currents. The motion of the equatorward borders of intense currents on the nightside seems to correlate reasonably well with $D_{s t}$. But on the dayside the boundary motion does not well correlate with $D_{s t}$. It demonstrates that the latitudinal variation of the peak current densities on the dayside follows IMF $B_{z}$. These features are clearer when looking at Fig. 10, where the most-equatorward boundaries of currents densities on the dayside (nightside) are compared with the variations of $20 \mathrm{~min}(40 \mathrm{~min})$ time delayed IMF $B_{z}\left(D_{s t}\right)$ in the same format as Fig. 4. The motion of the equatorward borders of intense currents on the dayside correlates with $B_{z}$, while on the nightside it correlates reasonably well with $D_{s t}$.

The electrojet densities during the storm main phase (08:00 UT-17:00 UT) are compared with the ionospheric outputs of the SWMF, as shown in Fig. 11. CHAMP passes from the later afternoon (daytime) to the early morning (nighttime) (from left to right). The red curve depicts the model output and the black curve represents the satellite measurement. The positive currents on the dayside 

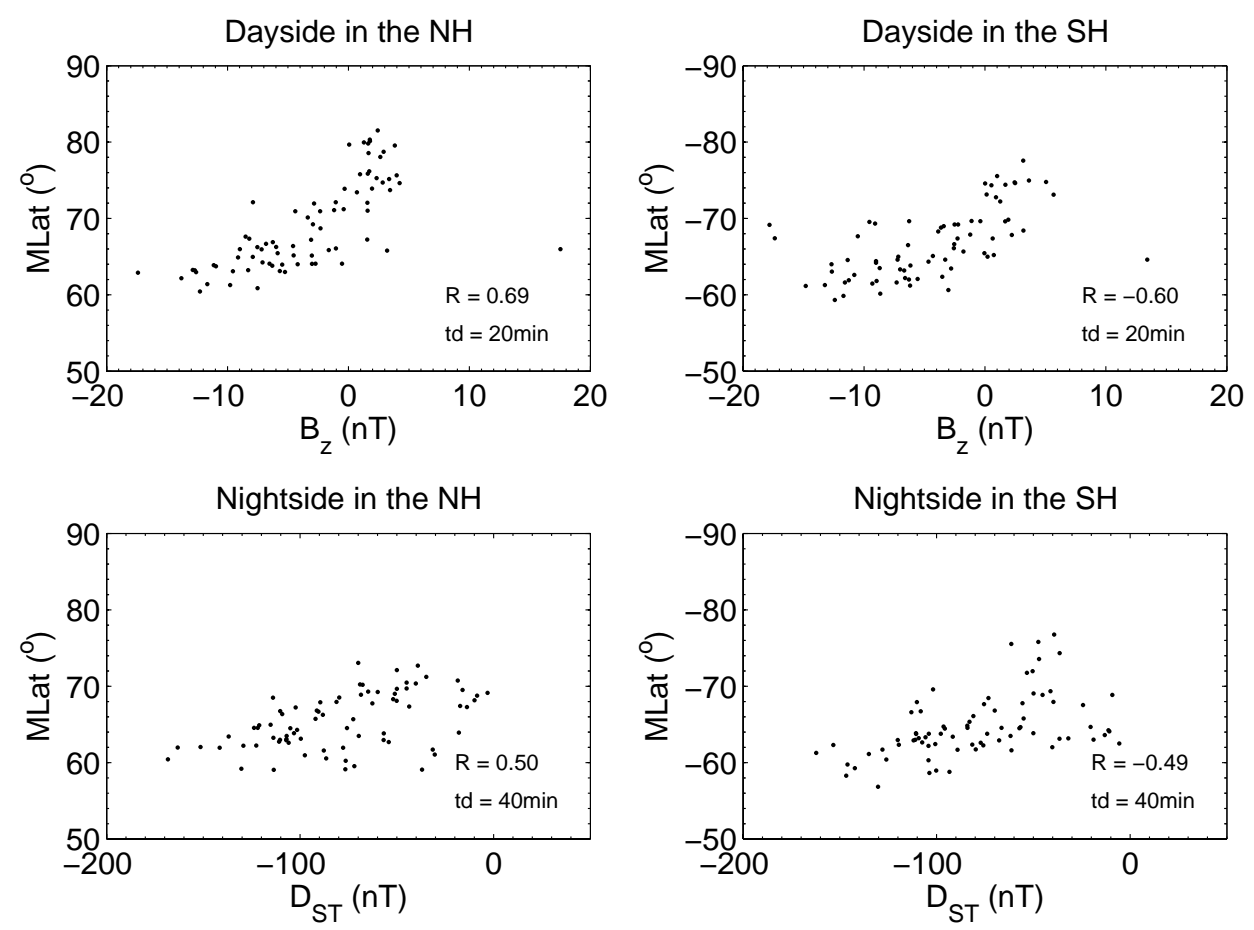

Fig. 10. The same as Fig. 4 but for the 17-21 April 2002 event.
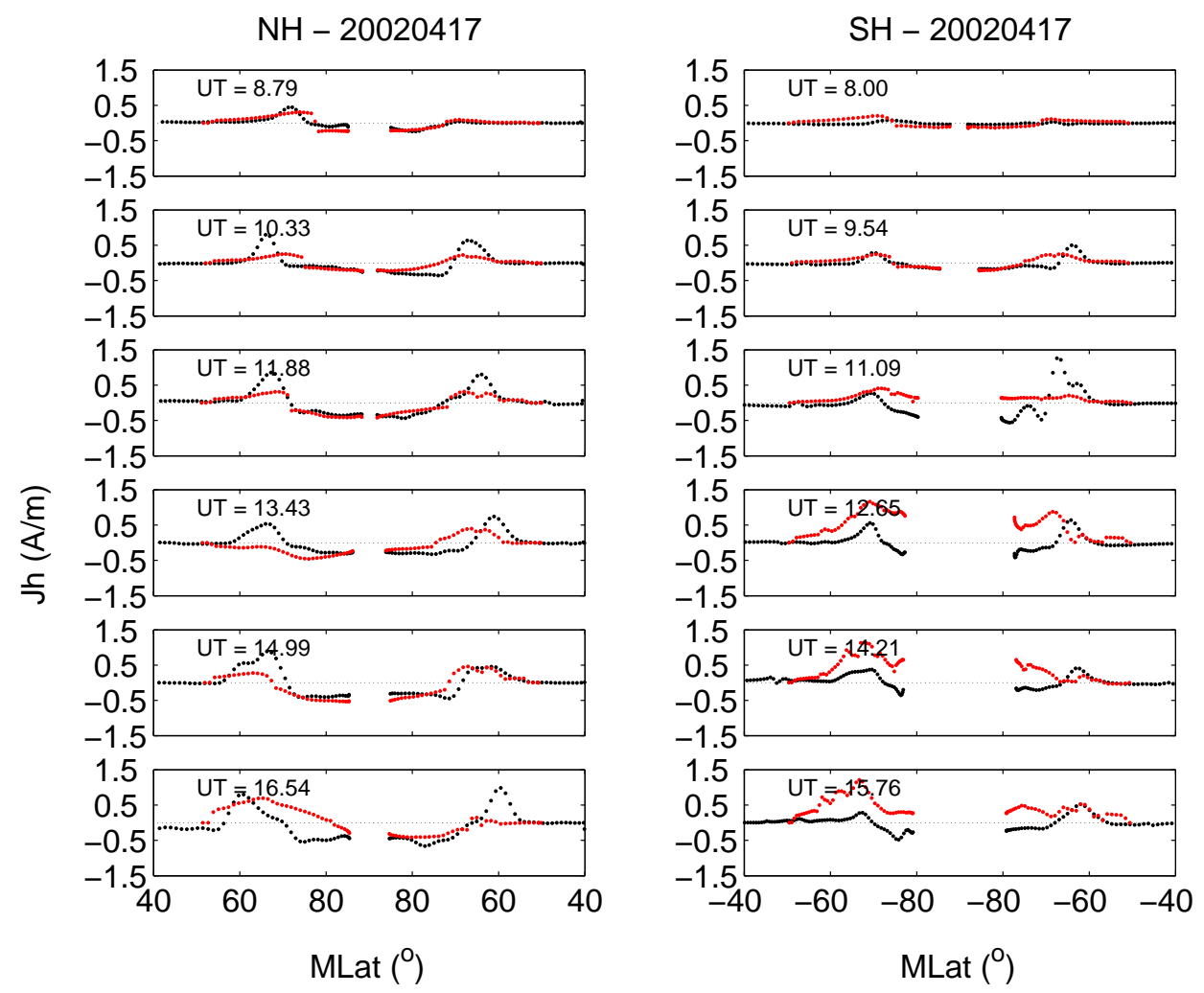

Fig. 11. The same as Fig. 5 but for the 17-21 April 2002 event. 

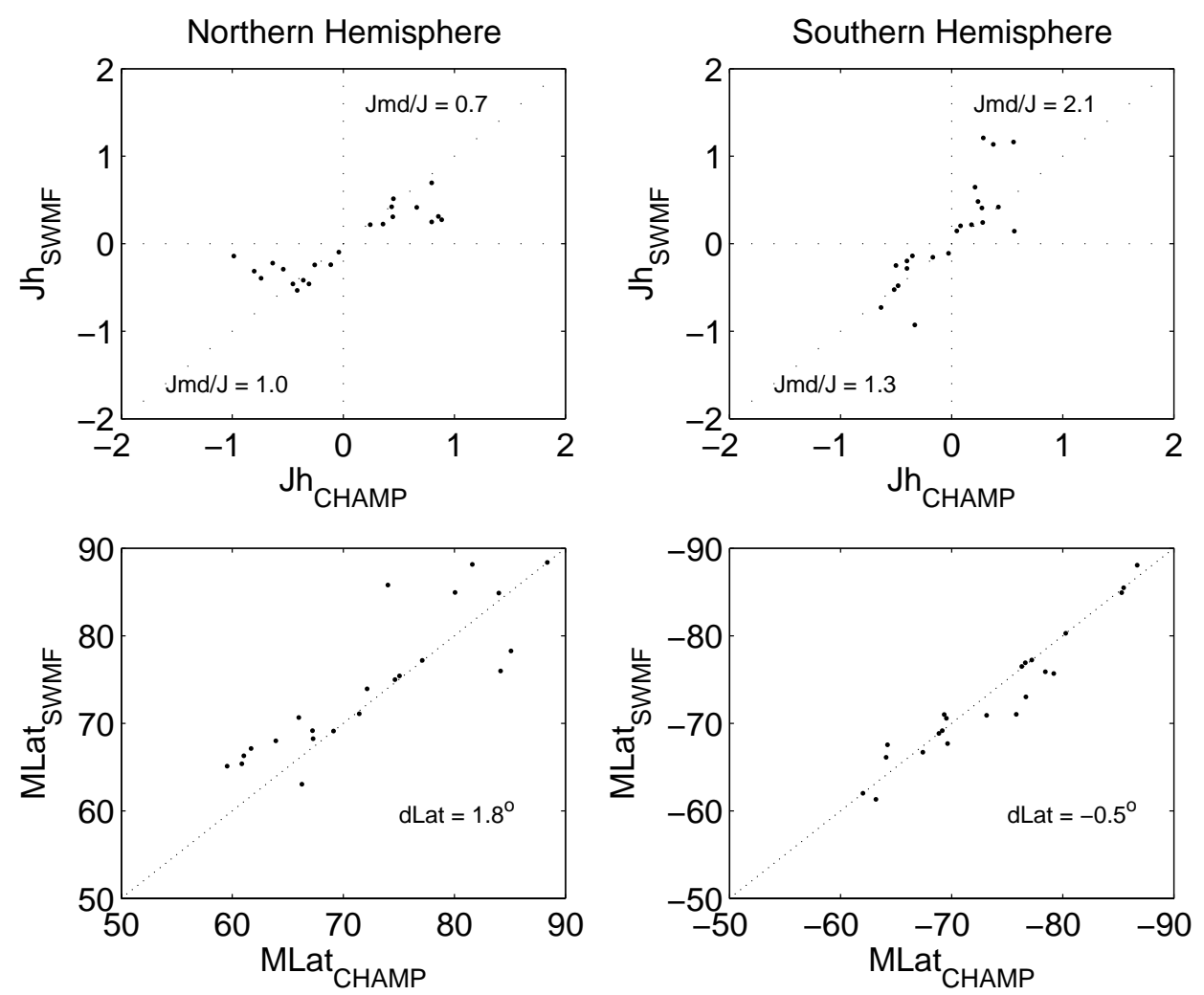

Fig. 12. The same as Fig. 6 but for the 17-21 April 2002 event.

correspond to eastward electrojets while on the nightside correspond to westward electrojets. SWMF underestimates the amplitudes of currents in the Northern Hemisphere and overestimates the amplitudes of currents in the Southern Hemisphere. In addition, model currents tend to be located more poleward than the observations, which is more obvious in the Northern Hemisphere than in the Southern Hemisphere. The top two panels in Fig. 12 show a comparison of the peak eastward (positive) and westward (negative) currents observed by CHAMP versus predictions by SWMF in both hemispheres. The average ratio between the model results and observations is about 0.7 (2.1) for eastward electrojets and about 0.8 (1.3) for westward electrojets in the Northern (Southern) Hemispheres. The bottom two panels show the latitudes of peak current densities observed by CHAMP versus predictions by SWMF. The model tend to locate currents $1.8^{\circ}\left(0.1^{\circ}\right)$ poleward of the observations in the Northern (Southern) Hemisphere. In summary, the present simulations can yield ranges of current densities and locations "quite well", although the exact prediction of the time series is still impossible.

\section{Discussion}

In the previous section we have presented observations of electrojets and some other features during the geomagnetic storms of March 2001 and April 2002. During these storms the CHAMP satellite was orbiting the Earth close to the early morning (nighttime) and late afternoon (daytime) meridian. This orbit allows us to compare features of the auroral currents on the dayside and nightside.

\subsection{Current density}

The above analysis shows that both eastward and westward electrojets flow during the storm periods, with the most intense currents appearing during the main phase of the storm, before $D_{s t}$ reaches its maximum. The peak current densities do not always coincide with the most equatorward currents. Table 1 lists the largest current densities encountered in each of the storms. Based on the values given in the table we believe that the dayside and nightside peak current densities are unrelated to each other. And even in the same local time sector largest current densities in opposite hemispheres are rarely observed during the same orbit. The correlations of the current densities are calculated versus the solar wind and IMF parameters. We find the highest correlation coefficients for $E_{m}$. Figure 13 shows relation of the peak densities of 
31 March 2001
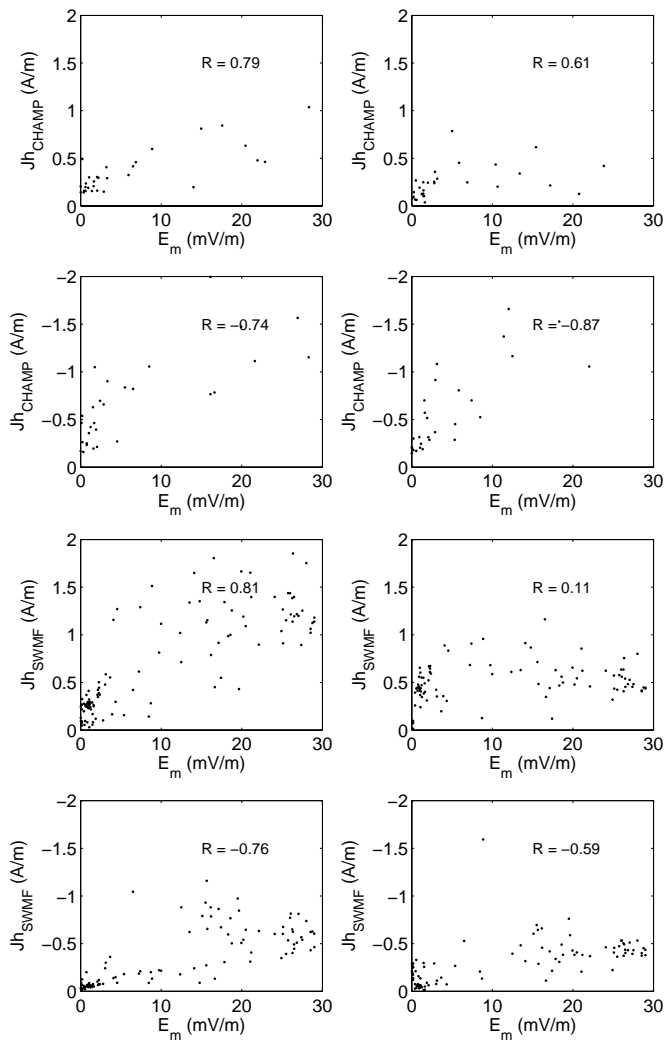
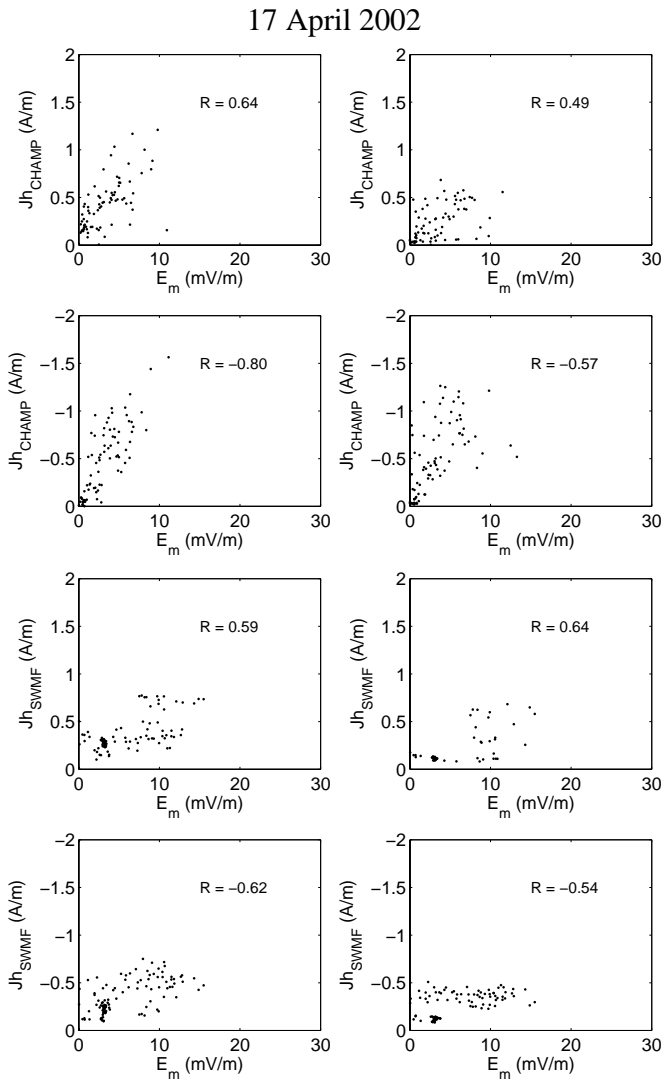

Fig. 13. The peak densities of the eastward and westward currents versus the merging electric field, $E_{m}$. The left panels are for the March storm and the right are for the April storm. The top two rows are for the CHAMP observations and the bottom are for the SWMF outputs. The model results are in the interval of $5 \mathrm{~min}$.

the westward and eastward electrojet, Jh, from CHAMP (top two rows) and SWMF (bottom two rows) with $E_{m}$ for both March and April storm events. Good correlations are found for them. It can be seen that Jh tends to increase as $E_{m}$ increases, which is the same for both the model and the observation. The saturation effect at $E_{m}>10 \mathrm{mV} / \mathrm{m}$ is also evident for both CHAMP data and SWMF prediction, suggesting the model can match the physical trend.

The current densities determined for these storm studies are on average a factor of 7 larger than the average electrojet density $(0.2 \mathrm{~A} / \mathrm{m})$. The westward electrojets on the nightside are on average larger by a factor of 1.8 (2.2) than the eastward electrojets on the dayside in the Northern (Southern) Hemisphere, therefore, making AL larger than AU during an intense storm (Kamide, 1979). The comparison of integrated current values on the dayside and nightside shows different pictures of the current densities. For the March storm the intensities of the integrated westward electrojets are larger than the eastward electrojets, but for the April storms, the intensities of the integrated eastward (westward) electrojets are larger than the westward (eastward) electrojets on the nightside (dayside). This is not surprising since the integrated current values take into account not only the intensity but also the electrojet width.

\subsection{Latitudinal variation}

During periods of enhanced solar wind input into the magnetosphere the auroral oval expands equatorward. Our results show that the centers of the peak densities of the eastward and westward auroral electrojets can expand to below $60^{\circ}$ MLat during the intense March storm (see Table 1). This is confirmed by Fig. 14, which shows the relationship between the MLat of the maximum westward and eastward electrojets versus the magnitudes of their current densities during these storms. The black dots denote CHAMP observations and the red circles SWMF outputs. The center of the currents during relatively quiet periods with current density lower than $0.5 \mathrm{~A} / \mathrm{m}$ can be found from latitudes higher than $\pm 75^{\circ}$ to as low as $\pm 60^{\circ}$. The auroral oval tends to expand equatorward as the current density increases, which is less obvious in the model data. The center of the electrojets can expand to $\pm 55^{\circ}$ when the peak current density is larger than $1 \mathrm{~A} / \mathrm{m}$ for the March storm, with a minimun $D_{s t}=-387 \mathrm{nT}$. The electrojet center shifts equatorward below $\pm 60^{\circ}$ when the peak current density is larger than $1 \mathrm{~A} / \mathrm{m}$ for the April storm, with a minimum $D_{s t}=-149 \mathrm{nT}$. Therefore the current AE network, which covers latitudes only down to $63^{\circ}$, might have problems in monitoring the actual auroral electrojets 

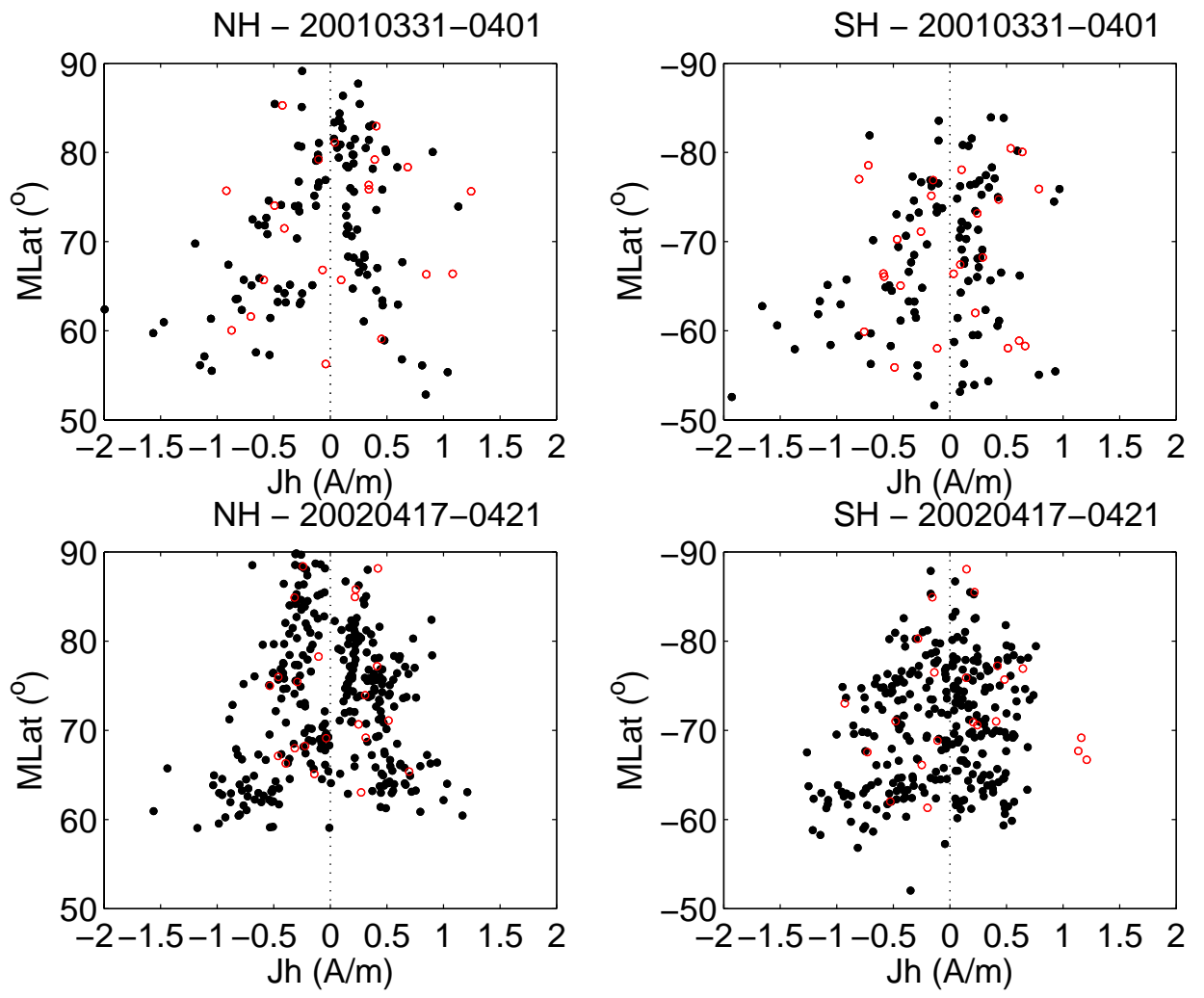

Fig. 14. The peak densities of the eastward and westward currents, as observed by CHAMP (black dot) and predicted by SWMF (red circle) versus the MLat where they were recorded. Results are from the 2001 (top) and 2002 (bottom) storms. Left is in the Northern Hemisphere and right is in the Southern Hemisphere.
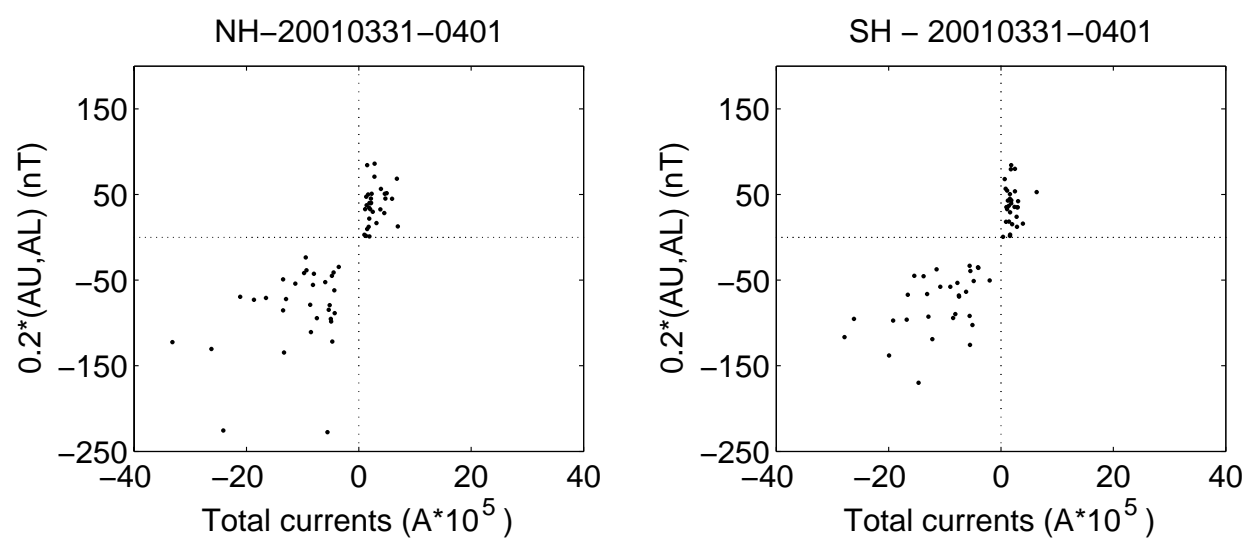

Fig. 15. The intensities of the integrated eastward and westward currents versus the amplitudes of AL, AU indices during the March storms. Left is in the Northern Hemisphere and right is in the Southern Hemisphere.

during moderate and intense geomagnetic storms. Thus the reported index may be substantially lower than the real values. To test this statement the integrated current intensities together with the magnitudes of $\mathrm{AU}, \mathrm{AL}$ indices for the intense March storm are shown in Fig. 15. Both AU and AL are averaged over the time period it takes CHAMP to pass the polar region. It can be seen clearly that in both hemispheres $\mathrm{AL}$ tends to saturate for larger current intensities, which is believed to be caused by the equatorward shift of the auroral electrojet beyond the standard AE network (Akasofu, 1981; Feldstein et al., 1997). 
It is shown that the dayside current boundary is displaced by a few degrees less equatorward than the nightside region near the peak of the magnetic storm, which is consistent with previous studies (Meng, 1986; Wang et al., 2005). The latitudinal variations of the auroral electrojets are compared with the variations of $D_{s t}$ and the interplanetary magnetic field component $B_{z}$ in order to determine how these parameters control the current configuration in the auroral region. As shown in Figs. 4 and 10, on the dayside, the equatorward shift of the eastward auroral electrojets appears to be controlled closely by the southward IMF $B_{z}$, while on the nightside the poleward retreat of the westward currents is more gradual during the recovery phase and the latitudinal motion of the equatorward boundary more correlated with the variation of $D_{s t}$ than with $B_{z}$. These results also show that the nightside equatorward and poleward movement, and the enhancement of the electrojets happen earlier than the development of the ring current. These findings suggest a closer relation of the ring current intensity with the processes in the magnetospheric tail and indicate that the nightside electrojets can be part of the ring current circuit (Pudovkin et al., 1968; Rostoker, 1997).

It is also noticed that westward electrojets cover a wider range of latitudes than the eastward electrojets for the March storm. The westward electrojets expand both poleward and equatorward while the eastward electrojets move only equatorward. A possible explanation could be the different drivers of the electrojets, the plasma convection and the explosive injection. In case of the early morning westward electrojet the intensified convection moves the currents equatorward and the substorm electrojet is characterized by a poleward jump. On the other hand both types of drivers make the eastward electrojet move equatorwards (Feldstein et al., 1997). This can explain the phenomena during the March storm. However, this is not true for the April storm during which eastward currents on the nightside cover a much wider region than westward currents.

\subsection{Data-model comparison}

When comparing satellite observations with SWMF outputs, we find that the model can reproduce the ranges of the current densities and locations well. In addition to the general correct trend, it is also found that the currents may be saturating for $E_{m}>10 \mathrm{mV} / \mathrm{m}$, which has been shown in both the model and actual data, suggesting that the model can match the physical trend. However, the exact prediction of the temporal development is still not good. For the March storm, on average, the model underestimates the westward current density by about $20 \%$ on the nightside, while it overestimates the eastward current by about $30 \%$ on the dayside. For the April storm, the model underestimates the currents in the Northern Hemisphere by about $30 \%$, but overestimate the current systems in the Southern Hemisphere by about $70 \%$.
The peak current densities occur not necessarily simultaneous in the CHAMP observations and SWMF results. For the March event, the model currents tend to be located $1.4^{\circ}$ MLat poleward of the observations in both hemispheres. For the April event, the model currents tend to be located $1.8^{\circ}$ poleward of the observations in the Northern Hemisphere, while they fit very well $\left(0.1^{\circ}\right)$ the observations in the Southern Hemisphere. One may notice that the currents observed by CHAMP are located more poleward in the Southern Hemisphere than in the Northern Hemisphere for the April storm, which may account for the hemispheric difference of the model performance. In general, the location of the maximum in the current density derived from SWMF suggests a polar cap boundary several degrees poleward of that observed by satellites during storm periods. This is consistent with previous studies which found that the locations of the maxima in the ionospheric potential and FAC density derived from SWMF are several degrees poleward of those observed by satellites during storm periods (Wang et al., 2008). Partially, this can be attributed to the inner boundary of the model $\left(3.5 R_{E}\right)$, corresponding to $55^{\circ}$ MLat in the ionosphere. Current systems at lower latitude cannot be reproduced. However, during severe storms, the currents are observed to expand equatorward beyond $50^{\circ}$ MLat, which is far below the inner boundary of the model.

Previous studies have proposed a number of different methods allowing the model currents to shift more equatorward, but all have disadvantages (e.g. Ridley et al., 2001). For example, one option is to move the inner boundary of the model closer to the Earth. However, this requires to take the higher wave speed into account and reduce the time step of the simulation. Another approach might be to increase the model's resolution in the inner boundary. Either of these solutions will cause the model to run much slower, a trade off which must be made in order to maintain accuracy. Other methods include coupling the MHD code to a more sophisticated inner magnetosphere model (e.g. Liemohn et al., 2001) or including artificial, simplistic R2 currents (Ridley et al., 2002). These may allow the equatorward part of FACs to be more accurately modeled.

\section{Conclusions}

In this study, we have investigated the Northern and Southern Hemisphere auroral current characteristics during the March 2001 and April 2002 magnetic storms. We have identified a number of auroral current characteristics during these storms.

1. The peak current intensities determined during the storms are on average a factor of 7 larger than avearge electrojets intensities.

2. The westward current densities on the nightside are on average 2 times larger than the eastward current densities on the dayside. 
3. Both eastward and westward electrojets are present during storm periods. The most intense currents appear during the main phase of the storm. The current densities are correlated best with the merging electric field and tend to saturate when $E_{m}>10 \mathrm{mV} / \mathrm{m}$.

4. The integrated current intensity of the westward currents are larger than that of the eastward currents on both the dayside and the nightside for the March storm, but for the April storm the currents further poleward are larger than those located more equatorward with opposite polarity.

5. The peak eastward, and westward auroral electrojet centers can expand to below $55^{\circ}$ MLat during intense storms. These electrojets flow well equatorward of the AE index monitoring stations.

6. The equatorward motion of currents on the dayside is, in general, correlated with the strength of the IMF southward component. The latitudinal motion of the equatorward currents in the nightside sector appears to be more correlated with the variation of the $D_{s t}$ index. When $B_{z}<-25 \mathrm{nT}$ or $D_{s t}<-300 \mathrm{nT}$, the latitudinal position of the electrojets saturates in both hemispheres.

7. The SWMF model can reproduce the ranges of the densities and locations of the storm time auroral currents well. Both the model and actual data show that the currents tend to saturate when $E_{m}>10 \mathrm{mV} / \mathrm{m}$, suggesting that the model can match the physical trend. However, the prediction of the temporal development of the currents is still not satisfatory.

A larger statistical study involving more magnetic storms is required to verify our results.

Acknowledgements. We thank ACE teams for providing solar wind and IMF data, and WDC C2 for Geomagnetism at Kyoto for providing $\mathrm{AU}, \mathrm{AL}$, and $D_{s t}$ indices data. The operational and data processing supports of the CHAMP mission by the German DLR and BMBF are greatly appreciated. We thank the CSEM at University of Michigan for developing the SWMF model. This work is supported by the NASA research grant F010639, NSF grant ATM0639336, and National Nature Science Foundation of China (No. 40604017).

Topical Editor M. Pinnock thanks J.-C. Cerisier and A. Viljanen for their help in evaluating this paper.

\section{References}

Ahn, B.-H., Chen, G. X., Sun, W., Gjerloev, J. W., Kamide, Y., Sigwarth, J. B., and Frank, L. A.: Equatorward expansion of the westward electrojet during magnetically disturbed periods, J. Geophys. Res., 110, A01305, doi:10.1029/2004JA010553, 2005.

Akasofu, S. I.: Interplanetary energy flux associated with magnetospheric substorms, Planet. Space. Sci., 27, 425-431, 1979.

Akasofu, S.-I.: Relationships between the AE and Dst indices during geomagnetic storms, J. Geophys. Res., 86, 4820-4822, 1981.
Akasofu, S.-I. and Chapman, S.: Magnetic Storms: The Simultaneous Development of the Main Phase (DR) and of Polar Magnetic Substorms (DP), J. Geophys. Res., 68, 3155-3158, 1963.

Akasofu, S.-I. and Yoshida, S.: Growth and Decay of the Ring Current and the Polar Electrojets, J. Geophys. Res., 71, 231-240, 1966.

Allen, J. H. and Kroehl, H. W.: Spatial and temporal distributions of magnetic effects of auroral electrojets as derived from AE indices, J. Geophys. Res., 80, 3667-3677, 1975.

Burke, W. J., Rubin, A. G., Maynard, N. C., Gentile, L. C., Sultan, P. J., Rich, F. J., de La Beaujardière, O., Huang, C. Y., and Wilson, G. R.: Ionospheric disturbances observed by DMSP at middle to low latitudes during the magnetic storm of June 4-6, 1991, J. Geophys. Res., 105, 18 391-18 406, doi:10.1029/ 1999JA000188, 2000.

Chapman, S. and Bartels, J.: "Geomagnetism", Clarendon, Oxford, 1940.

Davis, T. N. and Sugiura, M.: Auroral Electrojet Activity Index AE and Its Universal Time Variations, J. Geophys. Res., 71, 785803, 1966.

De Zeeuw, D. L., Sazykin, S., Wolf, R. A., Gombosi, T. I., Ridley, A. J., and Tóth, G.: Coupling of a global MHD code and an inner magnetospheric model: Initial results, J. Geophys. Res., 109, A12219, doi:10.1029/2003JA010366, 2004.

Feldstein, Y. I., Grafe, A., Gromova, L. I., and Popov, V. A.: Auroral electrojets during geomagnetic storms, J. Geophys. Res., 102, 14 223-14 236, doi:10.1029/97JA00577, 1997.

Grafe, A. and Feldstein, Y.: About the relationship between auroral electrojets and ring currents, Ann. Geophys., 18, 874-886, 2000, http://www.ann-geophys.net/18/874/2000/.

Kamide, Y.: Relation between substorms and storms, in: Dynamics of the magnetosphere, edited by: Akasofu, S. I., pp. 425-443, D. Reidel, Norwell, 1979.

Kan, J. R. and Lee, L. C.: Energy coupling function and solar windmagnetosphere dynamo, Geophys. Res. Lett., 6, 577-580, 1979.

Kan, J. R., Zhu, L., and Akasofu, S. I.: A theory of substorm: onset and subsidence, J. Geophys. Res., 93, 5624-5640, 1988.

Liemohn, M. W., Kozyra, J. U., Thomsen, M. F., Roeder, J. L., Lu, G., Borovsky, J. E., and Cayton, T. E.: Dominant role of the asymmetric ring current in producing the stormtime $D_{s t}^{*}$, J. Geophys. Res., 106(A6), 10 883-10 904, doi:10.1029/2000JA000326, 2001.

Meng, C. I.: Dynamic Variation of the Auroral Oval During Intense Magnetic Storms, J. Geophys. Res., 89, 227-235, 1986.

Moretto, T., Olsen, N., Ritter, P., and Lu, G.: Investigating the auroral electrojets with low altitude polar orbiting satellites, Ann. Geophys., 20, 1049-1061, 2002,

http://www.ann-geophys.net/20/1049/2002/.

Olsen, N.: A new tool for determining ionospheric currents from magnetic satellite data, Geophys. Res. Lett., 23, 3635-3638, doi: 10.1029/96GL02896, 1996.

Powell, K. G., Roe, P. L., Linde, T. J., Gombosi, T. I., and Zeeuw, D. L. D.: A solution-adaptive upwind scheme for ideal magnetohydrodynamics, J. Comp. Phys., 154, 284-309, 1999.

Pudovkin, M., Shumilov, O., and Zaitzeva, S.: Polar storms and development of the DR currents, Planet. Space Sci., 16, 891898, 1968.

Reigber, C., Lühr, H., and Schwintzer, P.: CHAMP mission status, Adv. Space Res., 30, 129-134, 2002. 
Ridley, A. J., De Zeeuw, D. L., Gombosi, T. I., and Powell, K. G.: Using steady state MHD results to predict the global state of the magnetosphere ionosphere system, J. Geophys. Res., 106, $30067-30076,2001$.

Ridley, A. J., Hansen, K. C., Tóth, G., De Zeeuw, D. L., Gombosi, T. I., and Powell, K. G.: University of Michigan MHD results of the Geospace Global Circulation Model metrics challenge, J. Geophys. Res., 107, A101290, doi:10.1029/2001JA000253, 2002.

Ridley, A. J., Gombosi, T. I., and DeZeeuw, D. L.: Ionospheric control of the magnetosphere: Conductance, Ann. Geophys., 22, 567-584, 2004, http://www.ann-geophys.net/22/567/2004/.

Ritter, P., Lühr, H., Viljanen, A., Amm, O., Pulkkinen, A., and Sillanpää, I.: Ionospheric currents estimated simultaneously from CHAMP satellite and IMAGE ground-based magnetic field measurements: A statistical study at auroral latitudes, Ann. Geophys., 22, 417-430, 2004, http://www.ann-geophys.net/22/417/2004/.

Rostoker, G.: The role of substorms in the formation of the ring current, in: Workshop on the Earth's trapped environment, edited by: Reeves, G. D., p.33-38, Woodbury, NY, 1997.

Rostoker, G. and Phan, T. D.: Variation of auroral electrojet spatial location as a function of the level of magnetospheric activity, J. Geophys. Res., 91, 1716-1722, 1986.

Siscoe, G. L. and Petschek, H. E.: On storm weakening during substorm expansion phase, Ann. Geophys., 15, 211-216, 1997, http://www.ann-geophys.net/15/211/1997/.

Toffoletto, F., Sazykin, S., Spiro, R., and Wolf, R.: Inner magnetospheric modeling with the Rice Convection Model, Space Sci. Rev., 107, 175-196, 2003.
Tóth, G., Sokolov, I. V., Gombosi, T. I., Chesney, D. R., Clauer, C. R., De Zeeuw, D. L., Hansen, K. C., Kane, K. J., Manchester, W. B., Oehmke, R. C., Powell, K. G., Ridley, A. J., Roussev, I. I., Stout, Q. F., Volberg, O., Wolf, R. A., Sazykin, S., Chan, A., Yu, B., and Kóta, J.: Space Weather Modeling Framework: A new tool for the space science community, J. Geophys. Res., 110, A12226, doi:10.1029/2005JA011126, 2005.

Tóth, G., Zeeuw, D., Gombosi, T. I., Manchester, W. B., Ridley, A. J., Sokolov, I. V., and Roussev, I. I.: Sun-to-thermosphere simulation of the 28-30 October 2003 storm with the Space Weather Modeling Framework, Space Weather, 5, S06003, doi:10.1029/2006SW000272, 2007.

Wang, H., Lühr, H., Ma, S. Y., and Ritter, P.: Statistical study of the substorm onset: its dependence on solar wind parameters and solar illumination, Ann. Geophys., 23, 2069-2079, 2005, http://www.ann-geophys.net/23/2069/2005/.

Wang, H., Lühr, H., Ma, S. Y., Weygand, J., and Skoug, R.: Fieldaligned currents observed by CHAMP during the intense 2003 geomagnetic storm events, Ann. Geophys., 24, 311-324, 2006, http://www.ann-geophys.net/24/311/2006/.

Wang, H., Ridley, A. J., and Lühr, H.: Validation of the Space Weather Modeling Framework with observations from DMSP and CHAMP, Space Weather, in press, doi:10.1029/2007SW000355, 2008.

Weimer, D. R., Reinleitner, L. A., Kan, J. R., Zhu, L., and Akasofu, S.-I.: Saturation of the auroral electrojet current and the polar cap potential, J. Geophys. Res., 95, 18 981-18 987, 1990.

Weimer, D. R., Ober, D. M., Maynard, N. C., Collier, M. R., McComas, D. J., Ness, N. F., Smith, C. W., and Watermann, J.: Predicting interplanetary magnetic field (IMF) propagation delay times using the minimum variance technique, J. Geophys. Res., 108, A11026, doi:10.1029/2002JA009405, 2003. 